\title{
Hematemesis as an Initial Presentation of Enteropathy-Associated T-Cell Lymphoma
}

Mehak Bassi $^{1}$, Sonmoon Mohapatra ${ }^{2}$, Parth Sharma ${ }^{3}$, Andrew Korman ${ }^{2}$, C.S. Pitchumoni ${ }^{2}$, Arkady Broder $^{2}$

1. Division of Internal Medicine, Saint Peter's University Hospital/Rutgers Robert Wood Johnson School of Medicine, New Brunswick, USA 2. Division of Gastroenterology and Hepatology, Saint Peter's University Hospital/Rutgers Robert Wood Johnson School of Medicine, New Brunswick, USA 3. Department of Internal Medicine, All India Institute of Medical Sciences, New Delhi, New Delhi, IND

Corresponding author: Mehak Bassi, dr.mehakbassi@gmail.com

\begin{abstract}
Enteropathy-associated T-cell lymphoma (EATL) is a tumor of intraepithelial T-lymphocytes arising in the small intestine. Based on the genetic profile, immunohistochemistry, and histology, EATL is divided into two subtypes. EATL type I occurs in individuals with celiac disease (CD) while EATL type II is a sporadic form that occurs in individuals without CD. Intensive chemotherapy and surgery are the mainstay treatment. However, despite the currently available treatment options, the five-year survival rate is only 9\%. EATL presents as abdominal pain, nausea, or slow gastrointestinal bleeding. Severe bleeding leading to hemodynamic instability is rarely known in EATL. Therefore, we present a unique case of EATL who presented with acute and severe gastrointestinal bleeding with no prior history of CD.
\end{abstract}

Review began 07/26/2021 Review ended 08/02/2021 Published 08/08/2021

๑) Copyright 2021

Bassi et al. This is an open access article distributed under the terms of the Creative Commons Attribution License CC-BY 4.0., which permits unrestricted use, distribution, and reproduction in any medium, provided the original author and source are credited.
Categories: Gastroenterology, Oncology

Keywords: non-responsive celiac disease, gluten-free diet, enteropathy associated t-cell lymphoma, intestinal t-cell lymphoma, extranodal lymphomas

\section{Introduction}

Enteropathy-associated T-cell lymphoma (EATL) is a T-cell lymphoma of the small intestine. It usually presents as abdominal pain and chronic gastrointestinal bleeding. However, EATL presenting as massive upper gastrointestinal bleeding is rare. The diagnosis of EATL is challenging and the clinical outcome of the patients is dismal. We present an illustrative report of an EATL case who presented with massive gastrointestinal bleeding with no previous history of CD.

\section{Case Presentation}

A 73-year-old Caucasian gentleman presented to the emergency department with massive hematemesis and melena. He also reported intermittent episodes of abdominal pain for three months. After adequate fluid resuscitation, he underwent upper endoscopy and colonoscopy which failed to localize the source of bleeding. Eventually, the bleeding stopped on its own and he was transferred to our hospital for further investigations. He did not report any prior similar episodes. On presentation to our hospital, his vital signs were normal. Physical examination revealed tenderness in the mid-abdomen region.

Laboratory investigations demonstrated anemia with hemoglobin of $9.4 \mathrm{~g} / \mathrm{dl}$, platelet count of $95 \times$ $10^{3} / \mathrm{mm}^{3}$, total bilirubin of $1.2 \mathrm{mg} / \mathrm{dl}$, and albumin of $2.2 \mathrm{~g} / \mathrm{dl}$. An upper and lower endoscopic procedure performed again showed no stigmata of bleeding. Because of the persistent abdominal pain, he underwent computed tomography (CT) of the abdomen and pelvis with contrast which showed a $5.2 \times 4.6 \mathrm{~cm}^{2}$ irregular mass involving the jejunum, with wall thickening about $1 \mathrm{~cm}$ with adjacent mesentery involving $1.2 \mathrm{~cm}$ rounded lymph nodes (Figure 1). Several bilateral lower lobe predominant pulmonary nodules were demonstrated in the CT scan. 


\section{Cureus}

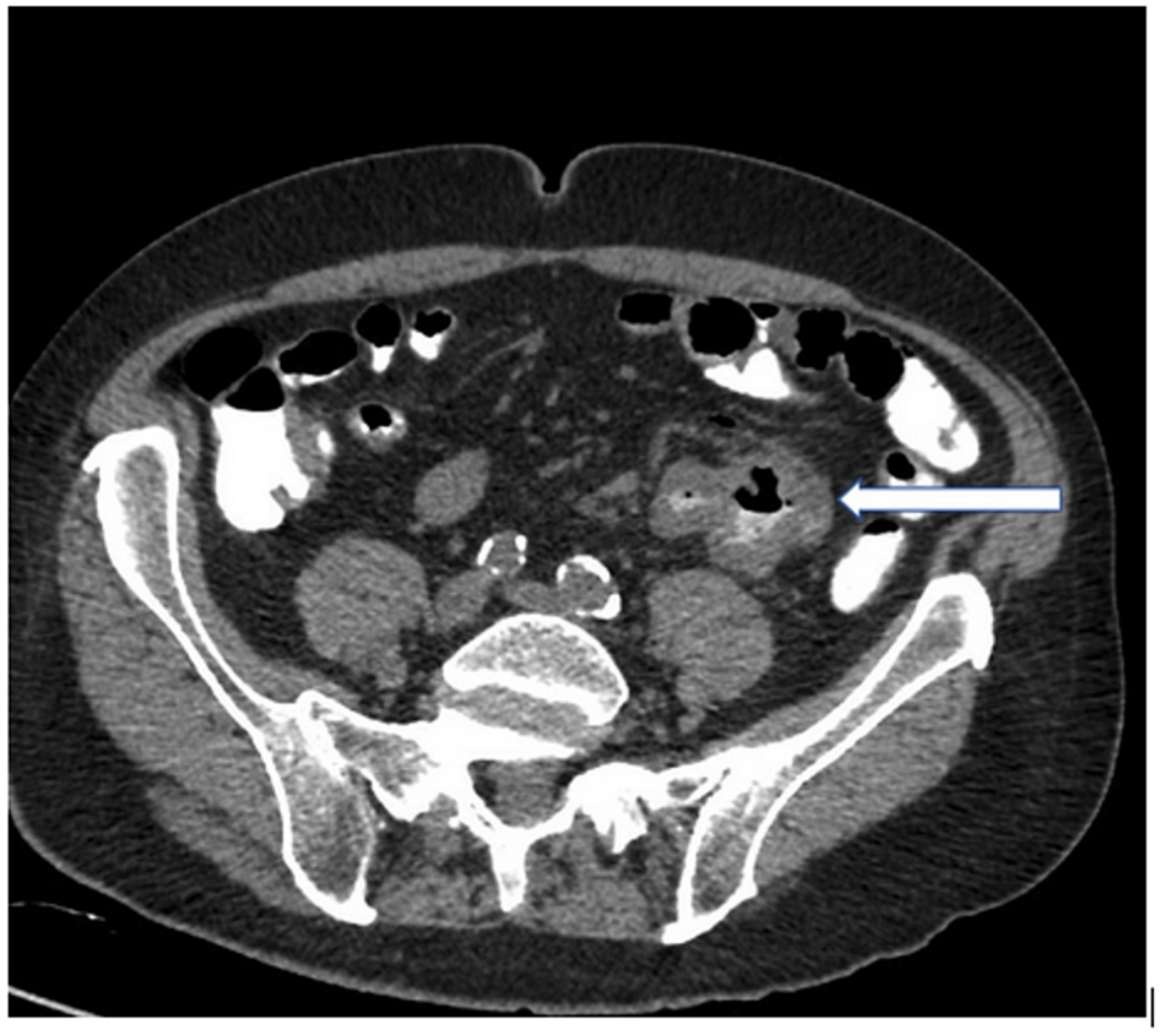

FIGURE 1: A $5.2 \mathrm{~cm} \times 4.6 \mathrm{~cm}$ irregular mass involving the jejunum

A small bowel enteroscopy was performed which demonstrated a $10 \mathrm{~cm}$, circumferential, polypoid, sessile infiltrative, and fungating mass in the mid-jejunum. Biopsy from the jejunal mass showed atypical T-cell infiltrates consistent with malignant T-cell lymphoma. It contained $10 \%$ of the lymphocytes, the majority expressed CD2 (82\%) and less CD3(51\%), 9\% of cells coexpress CD4/CD8 phenotype, which was consistent with enteropathy associated with T-cell lymphoma.

Immunostains were performed which revealed a population of $\mathrm{T}$ cells that are positive for CD3 and BCL2. Ki 67 showed a high proliferation rate (Figure 2). 


\section{Cureus}

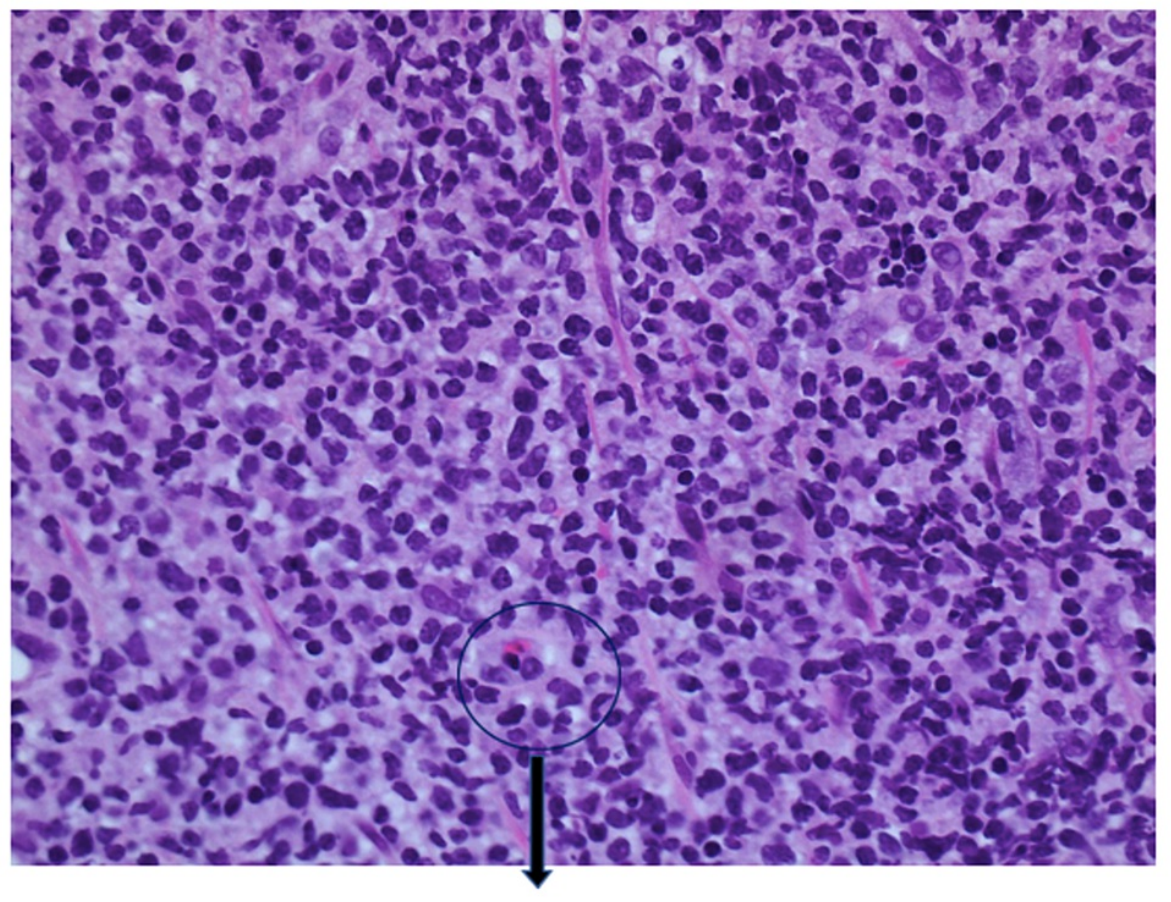

FIGURE 2: Biopsy of the Jejunal mass: the majority of the lymphocytes expressed CD2

Flow cytometry showed T-cell positive for $\mathrm{CD} 2, \mathrm{CD} 3$, and $\mathrm{CD}$ 7, with significantly decreased expression of CD5 and negative for CD4 and CD8. This pattern of expression is in support of T-cell lymphoma. The biopsy of the duodenal bulb demonstrated duodenal mucosa with focal epithelial infiltration of lymphocytes and focal villous blunting suggestive of $\mathrm{CD}$ (Figure 3).

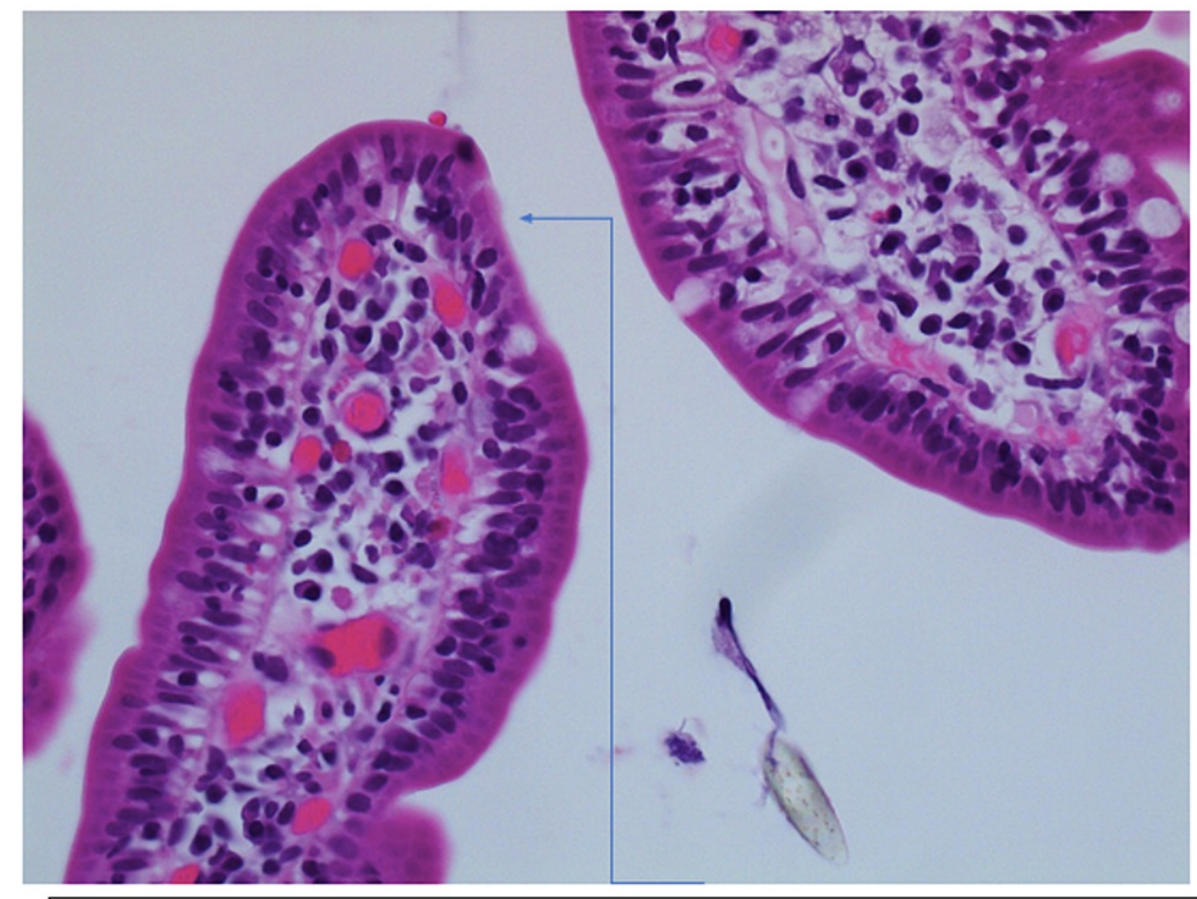

FIGURE 3: Biopsy of the duodenal bulb: duodenal mucosa with focal epithelial infiltration of the lymphocytes 


\section{Cureus}

nodes, compatible with lymph node metastases (Figure 4).

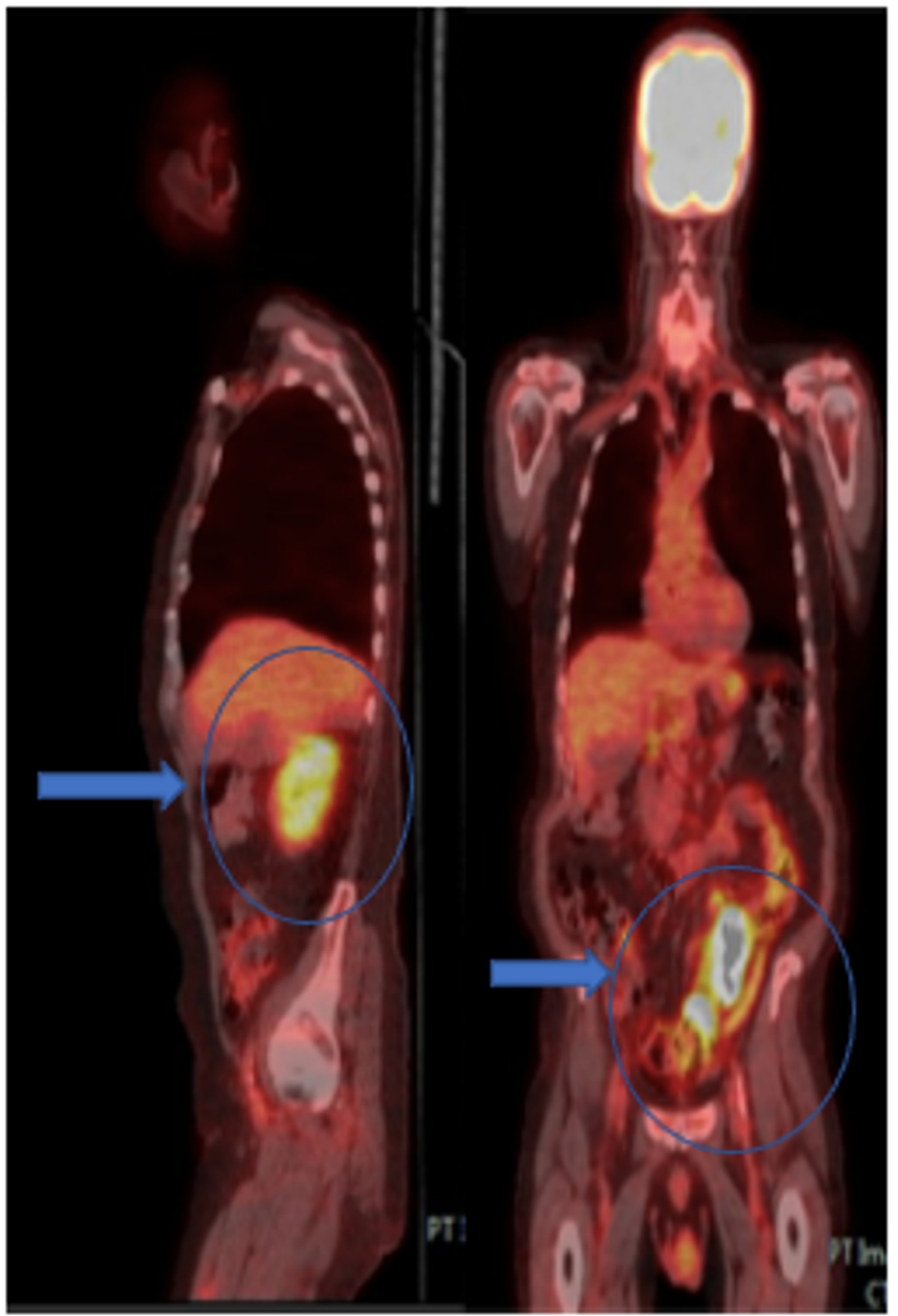

\section{FIGURE 4: A saggital and coronal view of the PET scan demonstrating} uptake in the jejunum with surrounding mesenteric lymph nodes

Although nonspecific, given the hypermetabolic nature of pulmonary nodules, they were considered malignant based on the clinical context. This high-grade tumor with metastasis to lymph nodes and lungs, pushed the multidisciplinary team to pursue a palliative course of action. The patient ultimately chose to be on hospice care.

\section{Discussion}

EATL is a rare tumor with a slightly higher male predominance and presents at a median age of 60 . EATL is peripheral or extranodal T-cell lymphoma arising in the small intestine and is commonly associated with $\mathrm{CD}$ [1]. It accounts for $4.2 \%$ of all peripheral T-cell lymphomas, which is more common in Europeans due to the increased incidence of celiac disease [2]. In the US, the incidence rate was 0.111 per $1,000,000$, with a higher incidence in Asians/Pacific Islanders [3,4]. The frequent site of involvement is observed in the jejunum, followed by the proximal ileum, colon, stomach, liver, and spleen $[5,6]$. It usually presents as abdominal pain, diarrhea, and weight loss. Small bowel obstruction and perforation are also frequently seen 
and may be the presenting symptom [7]. The tumor presents in forms of strictures, multifocal nodules, ulcers, and maybe even large masses, infiltrating mesenteric lymph nodes [8-10]. Slow gastrointestinal bleeding or occult bleeding has been reported in EATL [11]. Although, there are only a few case reports in the literature of EATL manifesting as sudden gastrointestinal bleeding [12,13]. Therefore, our case highlights a unique presentation of EATL, which presented as overt life-threatening bleeding.

The World Health Organization (WHO) describes two variants of EATL. Around $80-90 \%$ of the cases are type I EATL and type II EATL, a monomorphic variant of the disease [14]. Type 1 (classical) EATL is associated with the CD, with several of them having the CD-associated HLA-DQA $1 * 0501$, DBQ*0201 genotypes, and therefore, mostly seen in Northern Europe $[15,16]$. More than half of the patients with refractory celiac disease (RCD) are at increased risk of developing an EATL within five years. Adherence to a gluten-free diet has been shown to have a protective role against EATL type 1 lymphoma development [16,17]. EATL type 1 has CD3+, CD4-, CD8-, CD5-, CD7+, CD103+, CD56-, TCR-beta +/-cells, which mostly express CD30. In our case, since the histology was positive for CD3+ and negative for CD30, our patient had EATL type 1 lymphoma. The duodenal biopsy of our patient showed focal villous blunting with focal epithelial infiltration of lymphocytes which was consistent with celiac disease.

Type 2 EATL is most common in Asia, presents as a sporadic form with no prior history of CD [9]. The tumor cells express CD8+, CD4-, CD3+, and CD56+ [18,19]. A thorough diagnosis of EATL usually involves doubleballoon enteroscopy (DBE) or video capsule enteroscopy (VCE) to obtain histological samples. Video capsule endoscopy (VCE) demonstrates the location and extent of complications like small intestinal lesions and GI bleeding [20,21]. For staging of lymphoma and the presence of extranodal involvement, 18Ffluorodeoxyglucose positron emission tomography scan (18F-FDG-PET scan) and CT should be pursued [21,22]. PET scan is a more sensitive modality than CT for identifying EATL [23].

Non-compliance to a gluten-free diet, delayed diagnoses, age of diagnoses, and genomic homozygosity for HLA- DQ2 are identifiable as risk factors for malignant complications [6]. Combined modality therapy includes surgery with the possibility of subsequent anthracycline-based chemotherapy. Depending on tumor location, surgery is often utilized as a diagnostic and therapeutic modality [15]. The response rate of Anthracycline plus the CHOP regimen ranges between $42 \%$ and $58 \%$, while the five-year overall survival is around 20\% [6,12]. Alemtuzumab, a monoclonal antibody targeting CD52 on cancerous and healthy T cells, is used with chemotherapy with initially promising results for the remission of diseases [22]. Autologous stem cell transplantation is proven beneficial in selected patients with overall survival of $59 \%$ at four years [23].

Many studies have emphasized the importance of a gluten-free diet to avoid progression from celiac disease to T-cell lymphoma [24]. Developing newer diagnostic models, early referral to specialized centers, and early surgical intervention is warranted to improve patients' survival. Counseling patients with celiac disease regarding adherence to a gluten-free diet is of utmost importance. In addition to the literature, our case presenting as sudden gastrointestinal bleeding demonstrates an unusual presentation of EATL.

\section{Conclusions}

Enteropathy-associated T-cell lymphoma is an aggressive lymphoma of the small intestine. EATL usually presents as abdominal pain, vomiting, or gastrointestinal perforation. It is known to cause anemia by occult bleeding. However, our case presented with sudden and massive gastrointestinal bleeding as the initial manifestation. The prognosis of this disease is dismal. In this case, we review the current literature and raise awareness of an uncommon presentation of a rare tumor.

\section{Additional Information}

\section{Disclosures}

Human subjects: Consent was obtained or waived by all participants in this study. Conflicts of interest: In compliance with the ICMJE uniform disclosure form, all authors declare the following: Payment/services info: All authors have declared that no financial support was received from any organization for the submitted work. Financial relationships: All authors have declared that they have no financial relationships at present or within the previous three years with any organizations that might have an interest in the submitted work. Other relationships: All authors have declared that there are no other relationships or activities that could appear to have influenced the submitted work.

\section{References}

1. Marafini I, Monteleone G, Stolfi C: Association between celiac disease and cancer . Int J Mol Sci. 2020, 21:4155. 10.3390/ijms21114155

2. Foss FM, Horwitz SM, Civallero M, et al.: Incidence and outcomes of rare T cell lymphomas from the T Cell Project: hepatosplenic, enteropathy associated and peripheral gamma delta T cell lymphomas. Am J Hematol. 2020, 95:151-5. 10.1002/ajh.25674

3. Biagi F, Bianchi PI, Vattiato C, et al.: Influence of HLA-DQ2 and DQ8 on severity in celiac Disease . J Clin Gastroenterol. 2012, 46:46-50. 10.1097/MCG.0b013e318221077e 
4. Verbeek WH, Van De Water JM, Al-Toma A, Oudejans JJ, Mulder CJ, Coupé VM: Incidence of enteropathy-associated T-cell lymphoma: a nation-wide study of a population-based registry in The Netherlands. Scand J Gastroenterol. 2008, 43:1322-8. 10.1080/00365520802240222

5. Delabie J, Holte H, Vose JM, et al.: Enteropathy-associated T-cell lymphoma: clinical and histological findings from the international peripheral T-cell lymphoma project. Blood. 2011, 118:148-55. 10.1182/blood-2011-02-335216

6. Gale J, Simmonds PD, Mead GM, Sweetenham JW, Wright DH: Enteropathy-type intestinal T-cell lymphoma: clinical features and treatment of 31 patients in a single center. J Clin Oncol. 2000, 18:795-803. 10.1200/JCO.2000.18.4.795

7. Sieniawski M, Angamuthu N, Boyd K, et al.: Evaluation of enteropathy-associated T-cell lymphoma comparing standard therapies with a novel regimen including autologous stem cell transplantation. Blood. 2010, 115:3664-70. 10.1182/blood-2009-07-231324

8. Zettl A, deLeeuw R, Haralambieva E, Mueller-Hermelink HK: Enteropathy-type T-cell lymphoma. Am J Clin Pathol. 2007, 127:701-6. 10.1309/nw2bk1dxb0eqg55h

9. Arps DP, Smith LB: Classic versus type II enteropathy-associated T-cell lymphoma: diagnostic considerations. Arch Pathol Lab Med. 2013, 137:1227-31. 10.5858/arpa.2013-0242-CR

10. Isaacson PG, Du MQ: Gastrointestinal lymphoma: where morphology meets molecular biology . J Pathol. 2005, 205:255-74. 10.1002/path.1703

11. Kinaci E, Gunes ME, Huq GE: An unusual presentation of EATL type 1: emergency surgery due to lifethreatening gastrointestinal bleeding. Int J Surg Case Rep. 2013, 4:961-4. 10.1016/j.ijscr.2013.08.007

12. Gwiggner M, Patel P: An unusual case of obscure gastrointestinal bleeding in a patient with coeliac disease . Case Rep Gastrointest Med. 2011, 2011:634684. 10.1155/2011/634684

13. Al-Toma A, Verbeek WH, Hadithi M, von Blomberg BM, Mulder CJ: Survival in refractory coeliac disease and enteropathy-associated T-cell lymphoma: retrospective evaluation of single-centre experience. Gut. 2007, 56:1373-8. 10.1136/gut.2006.114512

14. Di Sabatino A, Corazza GR: Coeliac disease. Lancet. 2009, 373:1480-93. 10.1016/S0140-6736(09)60254-3

15. Chander U, Leeman-Neill RJ, Bhagat G: Pathogenesis of enteropathy-associated T cell lymphoma. Curr Hematol Malig Rep. 2018, 13:308-17. 10.1007/s11899-018-0459-5

16. Chan JK, Chan AC, Cheuk W, Wan SK, Lee WK, Lui YH, Chan WK: Type II enteropathy-associated T-cell lymphoma: a distinct aggressive lymphoma with frequent $\gamma \delta$ T-cell receptor expression. Am J Surg Pathol. 2011, 35:1557-69. 10.1097/PAS.0b013e318222dfcd

17. Roberti A, Dobay MP, Bisig B, et al.: Type II enteropathy-associated T-cell lymphoma features a unique genomic profile with highly recurrent SETD2 alterations. Nat Commun. 2016, 7:12602. 10.1038/ncomms 12602

18. Joyce AM, Burns DL, Marcello PW, Tronic B, Scholz FJ: Capsule endoscopy findings in celiac disease associated enteropathy-type intestinal T-cell lymphoma. Endoscopy. 2005, 37:594-6. 10.1055/s-2005861322

19. Hadithi M, Al-toma A, Oudejans J, van Bodegraven AA, Mulder CJ, Jacobs M: The value of double-balloon enteroscopy in patients with refractory celiac disease. Am J Gastroenterol. 2007, 102:987-96. 10.1111/j.1572-0241.2007.01122.x

20. Mallant M, Hadithi M, Al-Toma AB, et al.: Abdominal computed tomography in refractory coeliac disease and enteropathy associated T-cell lymphoma. World J Gastroenterol. 2007, 13:1696-700. 10.3748/wjg.v13.i11.1696

21. Hadithi M, Mallant M, Oudejans J, van Waesberghe JH, Mulder CJ, Comans EF: 18 F-FDG PET versus CT for the detection of enteropathy-associated T-cell lymphoma in refractory celiac disease. J Nucl Med. 2006, 47:1622-7.

22. Vivas S, Ruiz de Morales JM, Ramos F, Suárez-Vilela D: Alemtuzumab for refractory celiac disease in a patient at risk for enteropathy-associated T-cell lymphoma. N Engl J Med. 2006, 354:2514-5. 10.1056/NEJMc053129

23. Jantunen E, Boumendil A, Finel H, et al.: Autologous stem cell transplantation for enteropathy-associated T-cell lymphoma: a retrospective study by the EBMT. Blood. 2013, 121:2529-32. 10.1182/blood-2012-11466839

24. Itzlinger A, Branchi F, Elli L, Schumann M: Gluten-free diet in celiac disease-forever and for all? . Nutrients. 2018, 10:1796. 10.3390/nu10111796 